\title{
REPERCUSSÕES DA COVID-19 NO COTIDIANO DAMULHER: REFLEXÕES SOB O OLHAR SOCIOLÓGICO DE MICHEL MAFFESOLI
}

\author{
Margaret Olinda de Souza Carvalho Lira ${ }^{1}$ \\ Fernando Vitor Alves Campos ${ }^{1}$ \\ Levi Olinda Lira de Paiva \\ Jeany Freire Oliveira ${ }^{1}$
}

\author{
https://orcid.org/0000-0003-0309-8499 \\ https://orcid.org/0000-0002-7016-4196 \\ https://orcid.org/0000-0002-7032-062X \\ https://orcid.org/0000-0002-4181-2326
}

Objetivo: Refletir sobre as repercussões da pandemia do novo coronavírus na vida cotidiana da mulher. Método: Estudo teórico-reflexivo embasado em discussões vigentes sobre a pandemia em interface entre sustentabilidade e equidade de gênero, com análise fundamentada em noções e pressupostos da Sociologia Compreensiva e do Quotidiano por Michel Maffesoli. Resultados: Foram previstas repercussões econômicas, emocionais, na segurança e autonomia da mulher. Nas econômicas prevê-se crescimento do desemprego. As emocionais supõe-se que a mulher chegará à exaustão e atingirá seu limiar de tolerância expresso em incertezas, medo, angústia, raiva, preocupação, impotência e frustrações, atingindo com maior intensidade, as profissionais de enfermagem. As repercussões na segurança e autonomia se darão pela maior exposição à violência doméstica e ausência feminina nos processos decisórios sobre a doença. Conclusão: a trágica crise representa empecilho para a conquista da autonomia feminina e aponta para drásticas modificações na vida da mulher, cuja sobrevivência exigirá adaptações a uma nova rotina e incluirá mudanças de hábitos, esforço pessoal e solidariedade de amigos e instituições. Este material reúne informações relevantes que contribuem para a sensibilização e esclarecimento da sociedade sobre o quadro que se configura, compreendendo que modificações somente ocorrerão quando as atuais assimetrias entre homens e mulheres forem superadas.

Descritores: Infecções por Coronavirus; Mulher; Equidade de Gênero; Atividades Cotidianas; Desenvolvimento Sustentável.

\section{REPERCUSSIONS OF COVID-19 IN WOMEN'S DAILY LIFE: REFLECTIONS UNDER MICHEL MAFFESOLI'S SOCIOLOGICAL VIEW}

Objective: to reflect about repercussions of the pandemic caused by the new coronavirus in the daily life of women. Method: theoretical-reflective study based on current discussions on the pandemic at the interface between sustainability and gender equity, with analysis based on notions and assumptions of Comprehensive Sociology and Daily Life by Michel Maffesoli. Results: economic, emotional, security and women's autonomy repercussions were predicted. About economics is expected to increase unemployment. The emotional ones assume that the woman will reach exhaustion and reach her tolerance threshold expressed in uncertainties, fear, anguish, anger, concern, impotence, and frustrations, reaching nursing professionals with greater intensity. The repercussions on security and autonomy will occur due to the greater exposure to domestic violence and the absence of women in decision-making processes about the disease. Conclusion: the tragic crisis represents an obstacle to the achievement of female autonomy and points to drastic changes in the life of women, whose survival will require adaptations to a new routine and will include changes in habits, personal effort and solidarity from friends and institutions. This material gathers relevant information that contributes to the awareness and clarification of society about the situation that is taking shape, understanding that changes will only occur when the current asymmetries between men and women are overcom.

Descriptors: Women; Gender Equity; Activities of Daily Living; Coronavirus Infections; Sustainable Development.

\section{REPERCUSIONES DEL COVID-19 EN EL DIARIO DE LA MUJER: REFLEXIONES BAJO LA VISIÓN SOCIOLÓGICA DE MICHEL MAFFESOLI}

Objetivo: reflexionar sobre las repercusiones de la pandemia causada por el nuevo coronavirus en la vida cotidiana de las mujeres. Método: estudio teórico-reflexivo basado en debates actuales sobre la pandemia en la interfaz entre sostenibilidad y equidad de género, con análisis basado en nociones y suposiciones de Sociología integral y vida cotidiana por Michel Maffesoli. Resultados: se predijeron repercusiones económicas, emocionales y de seguridad y autonomía de la mujer. En la economía, se espera que el desempleo crezca. En los aspetos emocionales suponen que la mujer alcanzará el agotamiento y alcanzará su limite de tolerancia expresado en incertidumbres, miedo, angustia, ira, preocupación, impotencia y frustraciones, llegando a profesionales de enfermería con mayor intensidad. Las repercusiones em la seguridad y la autonomía se producirán debido a la mayor exposición a la violencia doméstica y la ausencia de mujeres en los procesos de toma de decisiones sobre la enfermedad. Conclusión: la trágica crisis representa un obstáculo para el logro de la autonomía femenina y apunta a cambios drásticos en la vida de las mujeres, cuya supervivencia requerirá adaptaciones a una nueva rutina e incluirá cambios en los hábitos, el esfuerzo personal y la solidaridad de amigos e instituciones. Este material reúne información relevante que contribuye a la conciencia y la clarificación de la sociedad sobre la situación que está tomando forma, entendiendo que los cambios solo ocurrirán cuando se superen las asimetrías actuales entre hombr. Descriptores: Mujeres; Equidad de Género; Actividades Cotidianas; Infecciones por Coronavirus; Desarrollo Sostenible.

${ }^{1}$ Universidade Federal do Vale do São Francisco, Petrolina, PE, Brasil.

2Unipê- Centro Universitário de João Pessoa- PB

Autor Correspondente: Margaret Olinda de Souza Carvalho Lira Email: olindalira@gmail.com

Recebido: 30/6/20 Aceito: 07/8 
INTRODUÇÃO

A pandemia provocada pelo novo coronavírus, o SARS-Cov2 tem provocado mudanças no modo de viver das famílias e comunidades ${ }^{1}$ em um trágico cotidiano que acentua iniquidades sociais, deixa transparecer as desigualdades entre os gêneros e exacerba a inferioridade feminina, com claras evidências de que os impactos dessa crise são diferentes para homens e mulheres e que elas estão sendo mais atingidas em seus direitos ${ }^{2}$.

Neste contexto, independentemente do espaço em que atuem, no trabalho ou no ambiente doméstico, mulheres estão sendo prejudicadas pela superioridade masculina. No espaço doméstico estão submetidas a uma carga de trabalho adicional, pois além das atividades costumeiras, incube-se a elas, a responsabilidade de cuidar da família, intensificando o desempenho de um elenco de atividades não remuneradas, que por não serem reconhecidas como trabalho, se tornam invisiveis ao mercado e, portanto, excluídas das estatísticas oficiais $^{3}$.

Somado a isso, é preciso ressaltar que, se por um lado o distanciamento social protege ou impede o contágio pelo virus, por outro, expõe a mulher à violência doméstica, uma vez que, confinada no mesmo espaço que o seu agressor ampliam-se as chances de vir a sofrer violência.

A submissão feminina também se apresenta no campo do emprego e renda, indicando que em decorrência da pandemia, mulheres estão e continuarão a ser mais impactadas economicamente, sobretudo para o significado percentual com ocupações informais que na maioria já perderam suas fontes de renda diária e terão mais dificuldade para reconquistar seus espaços².

Quanto às mulheres profissionais da saúde, que estão na linha de frente no combate à pandemia, constituem $70 \%$ da força de trabalhado em saúde e estão sobrecarregadas ${ }^{4}$. No Brasil, particularmente em relação à Enfermagem, estudo comprova que a profissão, além de ser maioria entre os trabalhadores da saúde e da força de trabalho do Sistema Único de Saúde (SUS), é predominantemente $(84,6 \%)$ constituída por mulheres 5 . De modo que, apesar de sua essencialidade no combate à pandemia prevê-se que estas serão desproporcionalmente afetadas ${ }^{2}$.

Por este encadeamento de ideias, este debate tem por interesse refletir sobre os efeitos da crise provocada pelo novo coronavirus, na vida cotidiana da mulher e sua interface entre equidade de gênero e sustentabilidade. Com isso, questiona-se: Os possiveis limites de tolerância e a força da mulher para sobreviver a esse trágico vivido e, o que está sendo feito para apoiá-la a superar esses danos? Também interessa saber como se dá a participação da mulher nos processos decisó- rios no combate à pandemia e a influência dessa participação no alcance da sustentabilidade? Diante disto, o objetivo do presente estudo é refletir sobre as repercussões da pandemia do novo coronavírus na vida cotidiana da mulher.

\section{Sociologia compreensiva e do quotidiano no pensamento de Michel Maffesoli}

Trata-se de uma análise teórica reflexiva elaborada com base em discussões vigentes sobre COVID-19, equidade de gênero e sustentabilidade, explorada sob a ótica da Sociologia Compreensiva e do Quotidiano, pelo pensamento de Michel Maffesoli, considerando que sua sensibilidade traz elementos fundamentais que direcionam o pesquisador a perceber modificações no viver cotidiano. Deste modo, se adequa à compreensão de desdobramentos da atual crise no cotidiano da mulher.

Michel Maffesoli, considerado pela crítica o mais importante teórico da Sociologia Contemporânea, se interessa pela sociedade atual, "o mundo vivido" o senso comum e o tempo presente, com valorização do fato corriqueiro, aquele que acontece no dia a dia das pessoas em diferentes cenários e sem se preocupar em explicá-lo, ele afirma que basta compreendê-lo, sendo esse, o foco da Sociologia Compreensiva, ou como ele alcunha "Sociologia do lado de dentro".

Subentendendo-se que compreender a subjetividade que permeia a vida cotidiana em seu constante movimento, implica em usar a sensibilidade para perceber o que se esconde nas entrelinhas. Para isso, o autor se ampara em Noções e em cinco Pressupostos Teóricos e da Sensibilidade, a saber: crítica ao dualismo esquemático, forma, sensibilidade relativista, pesquisa estilística e o pensamento libertário ${ }^{6}$.

De maneira que, para refletir sobre efeitos de um problema complexo que envolve múltiplas realidades, experiências e emoções, optou-se por trabalhar o pressuposto "a forma", analogia aplicada pelo autor para criticar o modo reducionista, elaborado pela sociologia tradicional, para descrever o fato social ou as cenas da vida cotidiana, em seu constante dinamismo.

A lógica formista destaca a maneira como alguma coisa se apresenta no instante atual ou no tempo presente, entendendo-a como um recorte de um todo. Por essa lente, nada é pré-determinado e em outro momento tudo pode se apresentar diferente ou de maneira mais abrangente.

Metodologicamente, para analisar situações da vida cotidiana, a noção de forma põe em evidência modulações imaginárias, que semelhantes a uma paleta de cores, variam o tom em categorias operatórias. Assim, diante do atual contexto da pandemia e seus possiveis desdobramentos no dia a dia da mulher, buscou-se trabalhar as seguintes modulações e suas 
correspondentes variações: presenteísmo, senso do limite e formas de resistência passiva.

O termo presenteísmo é usado para destacar a ambiência atual, ou seja, a sociedade contemporânea, que sob o ponto de vista da temporalidade se opõe ao futurismo moderno ${ }^{7}$. Como modulação o presenteísmo se desdobra nas categorias, alteridade e complementaridade. Sendo alteridade, um movimento acionado em situações de incompletude ou vazios existenciais.

Quanto ao Senso do limite, é assim denominado para identificar o limiar entre a tolerância e a tomada de consciência diante do trágico da vida cotidiana, que pode estar associado a acontecimentos traumáticos ou com ampla capacidade de modificar o dia a dia das pessoas.

Como modulação, o Senso do Limite, tem como variações, o trágico e a teatralidade, categorias que caminham juntas, sendo o trágico, o sentimento gerado pelas ocorrências da vida e a teatralidade, a maneira de expressá-lo. Em outras palavras, diante da emoção que envolve os acontecimentos da vida cotidiana, imaginariamente, pessoas se utilizam de máscaras, que lhes permitem encenar papéis e por meio desse recurso, expõem sentimentos trágicos advindos de diferentes motivações.

Já as formas de resistência passiva, constituem mecanismos utilizados por pessoas ou grupos para enfrentar ou se opor a uma situação de dominação ou opressão, de maneira que, sem entrar em confronto direto, encontram meios de protestar ou de se adaptar à situação, conforme as categorias de análise: aceitação da vida ou do destino, silêncio, astúcia, duplo jogo e solidariedade orgânica ${ }^{8}$.

Em sintese, aplicado ao momento atual, supõe-se que o trágico do cotidiano motivado pelo Novo Coronavírus, gera emoções e contribuem para que, imaginariamente, mulheres representem papéis para expor seus sentimentos. Para isso, utilizam diferentes mecanismos de sobrevivência para aceitar o destino trágico proporcionado por esta vivência. E assim, resistir, se adaptar e dar continuidade à sua vida. Deste modo, a presente noção sobre o quotidiano, descritas por Michel Maffesoli ajudará a compreender o drama que acredita- se, se expressará na vida cotidiana da mulher em decorrência da COVID-19.

\section{O covid-19 e as repercussões no cotidiano de vida da mulher}

A atual crise provocada pelo novo coronavírus está modificando significativamente o dia a dia da mulher, o que aponta para os seus efeitos negativos na vida cotidiana, com repercussões, sobretudo, nos aspectos emocionais, econômicos e na segurança, liberdade e autonomia da mulher. Tais categorias de repercussões serão discutidas nesta reflexão.

\section{REPERCUSSÕES EMOCIONAIS}

Nota-se que o senso de limite imposto pelo cenário trágico da pandemia, está levando mulheres à exaustão física e emocional. Diante disso, pressupõe-se que muitas destas chegarão ao limiar de tolerância e que utilizarão a emoção para expressar suas dores, frustrações, perdas, angústias, temores e incertezas, que são como pequenas mortes diárias?.

Também se projeta que os danos terão maior intensidade, quando se tratar de mulheres profissionais da saúde, sobretudo aquelas que compõem a equipe de Enfermagem na linha de combate à pandemia. Neste particular é importante ressaltar que por necessidade de sobrevivência muitas mulheres da equipe de Enfermagem assumem mais de um emprego, o que resulta em uma exaustiva carga horária de trabalho semanal, em alguns casos equivalendo a mais de 60 horas, interferindo negativamente no seu viver cotidiano e da familia ${ }^{10}$ diante de jornada que continua no espaço doméstico, uma vez que, devido a atributos socialmente construídos, ainda desempenham os papéis de dona de casa, esposa e mãe ${ }^{11}$.

Assim, é perceptível que as atuais vivências, têm gerado medo, angústia, raiva, preocupação, sensação de impotên$\mathrm{cia}^{12}$. Sentimentos que traduzem o medo do desconhecido, uma demonstração do não saber lidar com o que virá.

Certamente, a teatralidade funciona (e funcionará) como válvula de escape para externar inquietações e se opor ao poder do vírus. Mas sem necessariamente entrar no confronto direto, a mulher buscará identificar formas de aceitação ou mecanismos de resistência passiva, para se prevenir e sobreviver às incertezas impostas.

Na realidade da COVID-19, sobreviver exigirá da mulher a astúcia necessária para se adaptar a uma rotina diferente. Semelhante a um camaleão que muda de cor para se proteger do inimigo, driblar o vírus, exigirá mudança de hábitos, mantendo táticas de boas práticas de higiene pelo uso de máscaras e correta lavagem das mãos, além de evitar aglomerações. Depois, para superar os efeitos emocionais potencializados pela experiência, exigirá empenho da sua parte para acentuar suas forças latentes e solidariedade.

De modo que, diante dos impactos da COVID-19 na vida cotidiana de mulheres e meninas, a ONU-MULHERES ${ }^{2}$ alerta aos países, priorizá-las desenvolvendo estratégias promotoras de resiliência, geradoras de renda e alternativas de vida sustentáveis. No Brasil, senadoras e deputadas defendem direitos das mulheres na resposta do país à COVID-19 e propõem apoio a estas, na busca de alternativas para superar o problema e apoiá-las num momento tão delicado e desafiador como o da pandemia, que introduziu diversas mudanças na vida cotidiana da mulher, mães, esposa, trabalhadora, necessitando ressignificação do quotidiano. 


\section{REPERCUSSÕES ECONÔMICAS}

Em decorrência da pandemia, o enfoque econômico tem representado um grande problema na vida de muitas mulheres, pois diante dessa situação de emergência, necessitaram interromper suas atividades, sem que houvesse tempo para qualquer planejamento.

De maneira que, além do medo de ser acometida pela COVID-9, a atual crise está atingindo a mulher em seu direito econômico, com o aumento significativo de desemprego ${ }^{13} \mathrm{e}$ perda de fonte de renda para uma grande parcela com ocupações informais. Essas, não apenas perderam suas fontes de renda diária, como terão mais dificuldades para retornar ao ritmo de trabalho anterior. Assim, o aspecto econômico representará um grande problema que permanecerá após a pandemia com a precariedade do trabalho feminino, demonstração inconteste da desigualdade de gênero, cuja superação exigirá empenho politico no combate à informalidade e oportunidades mais igualitárias de emprego formal e melhor remuneração da mulher.

\section{REPERCUSSÕES NA SEGURANÇA, LIBERDADE E AUTONOMIA DA MULHER}

Informações internacionais apontam para o crescimento das agressões por parceiro íntimo, durante esse período, com três vezes mais denúncias na China e na França, em uma semana os casos aumentaram em $32 \%^{14}$. No Brasil, levantamentos parciais mostram crescimento de $18 \%$ nas denúncias, apenas no mês de março corrente ${ }^{15}$. Contudo, o fato de se encontrar impedida de sair, poderá contribuir para que a mulher não denuncie a agressão sofrida, em que já se acompanha diminuição das denúncias de violência doméstica em alguns estados, quando comparado ao mesmo período de $2019^{16}$. Elas recorrerão aos serviços de saúde em busca de amparo, mas provavelmente sentirão dificuldades para falar do vivido de agressão, o que exigirá da equipe profissional, olhar atento e atenção especial mediada por comunicação acolhedora que contribua para emergir a potência subterrânea existente na mulher agredida para que possa recomeçar a vida ${ }^{17}$.

Discussões também mostram preocupação com relação a pouca autonomia e participação da mulher nos processos decisórios relacionados à COVID-19, fator que impactará negativamente a sustentabilidade e distanciará o alcance de Objetivos para o Desenvolvimento Sustentável (ODS), sobretudo no que se refere à equidade de gênero e ao empoderamento feminino, pontos cruciais na conquista da sustentabilidade ${ }^{18}$.

Como é possivel perceber, isso remete a poderes e aponta para uma relação de dominação do instituinte para com o instituido, de onde emerge a força para sobreviver, importando manter essa luta, agora e uma vez que não se conhece o futuro, o que realmente faz sentido é valorizar o aqui e o agora, o presenteísmo em suas riquezas que precisam ser melhor exploradas ${ }^{6}$.

Desta forma, diante do atual momento, a visão presenteísta trazida por Michel Maffesoli serve arcabouço para expressar a transitoriedade dos acontecimentos da vida cotidiana e a importância ser sensivel e de exercer a alteridade.

Porque está claro que a pandemia gerará incompletudes e que a mulher precisará contar com o suporte social e afetivo de suas redes de pertencimento. Em todo o mundo, já é perceptivel que essa experiência trágica tem despertado a sensibilidade necessária para emergir uma solidariedade espontânea, nomeada "solidariedade orgânica"6, para traduzir a interação social por meio da qual, pessoas voluntariamente se organizam em rede, fortalecendo o vínculo social, diferentemente da solidariedade mecânica, que se estabelece por pura obrigação institucional?.

Com relação às mulheres profissionais de Enfermagem, já se percebe iniciativas solidárias de suporte emocional e orientações sobre hábitos saudáveis, por parte de redes sociais e organismos oficiais ${ }^{10}$.

\section{Limitações do Estudo}

O estudo apresenta como limitação o fato de, por tratar-se de artigo de reflexão, seus resultados apontarem para projeções que não podem ser generalizadas e que necessitarão de averiguação da sua concretização no cotidiano da mulher.

\section{Contribuições do Estudo para a Prática}

O presente estudo tem relevância social, considerando que as informações contribuirão com reflexões sobre repercussões da pandemia da COVID-19 no dia a dia da mulher, em especial das profissionais de Enfermagem, ampliarão o entendimento sobre desigualdade entre homens e mulheres e subsidiarão intervenções para a superação do atual momento por meio de oportunidades igualitárias e maior autonomia da mulher, requisitos para o alcance da equidade de gênero $e$ sustentabilidade.

\section{CONSIDERAÇÕES FINAIS}

Este breve panorama que traz a mulher como protagonista da trágica crise enredada pelo Novo Coronavírus, aponta para drásticas modificações no seu modo de viver, estando evidente que ela será afetada em seus direitos de segurança e liberdade, considerando que o problema intensificará as desigualdades e iniquidades de gênero historicamente existentes.

Fruto de uma cultura patriarcal que atribui prioritariamente à mulher o cuidado com a casa e com a família, muitas mulheres estão vivenciando a intensificação dessas responsabilidades durante a pandemia e não são poucas aquelas que 
estão assumindo sozinha a tarefa de cuidar de seus filhos. Muitas já estão desempregadas, outras, além de sobrecarregadas com os trabalhos domésticos, estão mais expostas à violência por parceiro íntimo.

Todos esses elementos reunidos melhoram o entendimento de que a mulher precisará se reinventar, deixando emergir a força subterrânea necessária para sobreviver e dar continuidade aos projetos de vida. Mas para que isso ocorra, precisará da solidariedade e da sensibilidade de suas redes de interações e de organismos institucionais, no sentido que todos os esforços sejam envidados nesse recomeço.

Contribuições dos Autores: Todos contribuíram em todas as etapas.

\section{REFERÊNCIAS}

1. Marques ES, Moraes CL, Halssemann MH, Deslandes SF, Reichenheim ME. A violência contra mulheres, crianças e adolescentes em tempos de pandemia pela COVID-19: panorama, motivações e formas de enfrentamento. Cad. Saúde Pública [Internet]. 2020 [cited 2020 jun 26]; 36(4):1-6. Available from: https://www.scielosp.org/article/csp/2020.v36n4/e00074420/.

2. Mulheres O.N.U. Gênero e Covid-19 na América Latina e no Caribe: dimensões de gênero na resposta. Declaração e Programa de Ação de Viena [internet]. 2020 [cited 2020 jun 25]. Available from: http://www.onumulheres.org.br/wp-content/uploads/2020/O3/ONU-MULHERES-COVID19_LAC.pdf.

3. Sousa IG. Economia do cuidado. Câmara dos deputados. Consultoria Legislativa [internet]. 2017 [cited 2020 jun. 02]. Available from: https://www2.camara.leg.br/atividade-legislativa/estudos-e-notas-tecnicas/publicacoes-da- consultoria-legislativa/fiquePorDentro/ temas/economia-do-cuidado-set-2017.

4. Boniol M, Mclsaac M, Xu L, Wuliji T, Diallo K, Campbell J. World Health Organisation. Gender equity in the health worfoce: Analysis of 104 countries [internet]. 2019 [cited 2020 jun.10]. Available from: https://apps.who.int/iris/bitstream/handle/10665/311314/WHO-HIS-HWFGender-WP1-2019.1-eng.pdf.

5. Fiocruz. Pesquisa inédita traça perfil da enfermagem no Brasil. Agência Fiocruz de Notícias [internet]. 2015 [cited 2020 jun 25 ]. Available from: https://portal.fiocruz.br/noticia/pesquisa-inedita-traca-perfil-da-enfermagem-no-brasil.

6. Maffesoli M. O tempo das tribos: o declínio do individualismo nas sociedades de massa. Rio de Janeiro: Forense Universitária; 2010.

7. Silva JM. Michel Maffesoli e a pós-modernidade como fenômeno de comunicação. Revista Midia e Cotidiano [internet]. 2020 [cited 2020 ju 15]. Available from: https://periodicos.uff.br/midiaecotidiano/article/view/Maffesoli\%20e\%20a\%20P\%C3\%B3s-Modernidade\%20 Juremir\%20Machado\%20da\%20Silva/20014.

8. Maffesoli M. A dinâmica da violência. São Paulo (SP): Revista dos Tribunais; 1987.

9. Maffesoli M. O mistério da conjunção: ensaios sobre comunicação, corpo e socialidade. Porto Alegre: Editora Sulina; 2009.

10. Machado MH, De Oliveira E, Lemos W, De Lacerda WL, Aguiar Filho W, Wermelinger M, Barbosa C. Mercado de Trabalho da Enfermagem: Aspectos Gerais. Enfermagem em Foco [internet]. 2016 [cited 2020 ago 02]; 7(ESP):35-62. Available from: http://revista.cofen.gov.br/ index.php/enfermagem/article/view/691/301.

11. Ximenes Neto FRG, Pessoa CV, Ximenes IT, Machado MH, Oliveira EM, Cunha ICKO. Características de Enfermeiros da Estratégia Saúde da Familia de uma Microrregião da Saúde do Ceará. Enfermagem em Foco [internet]. 2019 [cited 2020 ago 01]: 10(6):50-56. Available from: http://revista.cofen.gov.br/index.php/enfermagem/article/view/2908/679

12. Miranda FMA, Santana LL, Pizzolato AC, Saquis LMN. Condições de trabalho e o impacto na saúde dos profissionais de enfermagem frente a COVID-19. Cogitare Enferm [internet]. 2020 [cited 2020 jun 25]; 25. Available from: https://revistas.ufpr.br/cogitare/article/ view/72702/pdf.

13. Afonso P. O impacto da pandemia de COVID-19 na saúde mental. Revista Científica da Ordem dos Médicos [internet]. 2020 [Cited 2020 jun 26]; 33(5):351-358. Available from:https://www.actamedicaportuguesa.com/revista/index.php/amp/article/view/13877/5925.

14. Catalina L. Países registram aumento de violência doméstica durante período de quarentena; veja como denunciar casos no Ceará. Jornal, OPOVO online [internet]. 2020 [cited 2020 jun 26]. Available from: https://www.opovo.com.br/coronavirus/2020/03/30/paises-registram-aumento-de-violencia-domestica-durante-periodo-de-quarentena--veja-como-denunciar casos-no-ceara.html.

15. Ministério da Mulher, da Família e dos Direitos Humanos (BR). Coronavírus: sobe o número de ligações para canal de denúncia de violência doméstica na quarentena. Ouvidoria Nacional dos Direitos Humanos [internet]. 2020 [cited 2020 mar 28]. Available from: https:// www.gov.br/mdh/pt-br/assuntos/noticias/2020-2/marco/coronavirus-sobe-o-numero-de-ligacoes-para-canal-de-denuncia-de-violencia-domestica-na-quarentena.

16. Fórum Brasileiro de Segurança Pública. Nota técnica sobre Violência doméstica durante a pandemia de Covid-19. Decode [internet]. 2020 [cited 2020 mai 19]. Available from: http://forumseguranca.org.br/wp-content/uploads/2018/05/violencia-domestica-covid-19 v3.pdf.

17. Schelb M, Cunha MLO, Gottems LBD, Chariglione PFS. O processo de construção de material educativo para mulheres vitimas de violência. Enferm Foco [Internet]. 2019 [cited 2020 Ago 2]; 10(6):75-80. Available from: http://revista.cofen.gov.br/index.php/enfermagem/ article/view/2324/650.

18. Nações Unidas - Brasil. Objetivos de Desenvolvimento Sustentável: 17 para transformar nosso mundo. ONU [internet]. 2015 [Cited 2020 jun 26]. Avaliable from: https://nacoesunidas.org/pos2015/. 